\title{
Multivariate bathymetry-derived generalized linear model accurately predicts rockfish distribution on Cordell Bank, California, USA
}

\author{
Mary A. Young ${ }^{1, *}$, Pat J. Iampietro ${ }^{1}$, Rikk G. Kvitek ${ }^{1}$, Corey D. Garza ${ }^{2}$ \\ ${ }^{1}$ Seafloor Mapping Lab, California State University, Monterey Bay, 100 Campus Center, Bldg 13, Seaside, California 93955, USA \\ ${ }^{2}$ Marine Landscape Ecology Lab, California State University, Monterey Bay, 100 Campus Center, Bldg 53, Seaside, \\ California 93955, USA
}

\begin{abstract}
Accurate efficient estimation of actual and potential species distribution is a critical requirement for effective ecosystem-based management and marine protected area design. In this study we tested the applicability of a terrestrial landscape modeling technique in a marine environment for predicting the distribution of ecologically and economically important groundfish, using 3 species of rockfish at Cordell Bank National Marine Sanctuary (CBNMS) as a model system. Autoclassification of multibeam bathymetry along with georeferenced submersible video transect data of the seafloor and demersal fishes were used to model the abundance and distribution of rockfish. Generalized linear models (GLMs) were created using habitat classification analyses of high-resolution $(3 \mathrm{~m})$ digital elevation models combined with fish presence/absence observations. Model accuracy was assessed using a reserved subset of the observation data. The resulting probability of occurrence models generated at $3 \mathrm{~m}$ resolution for the entire $120 \mathrm{~km}^{2}$ study area proved reliable in predicting the distribution of all the species. The accuracies of the models for Sebastes rosaceus, S. flavidus and $S$. elongatus were 96,92 and $92 \%$, respectively. The probability of occurrence of $S$. flavidus and $S$. rosaceus was highest in the high relief rocky areas and lowest in the low relief, soft sediment areas. The model for $S$. elongatus had an opposite pattern, with the highest predicted probability of occurrence taking place in the low relief, soft sediment areas and a lower probability of occurrence in the rocky areas. These results indicate that site-specific and species-specific algorithmic habitat classification applied to high-resolution bathymetry data can be used to accurately extrapolate the results from in situ video surveys of demersal fishes across broad areas of habitat.
\end{abstract}

KEY WORDS: Ecosystem-based management · Rockfish · Groundfish · GLMs · Marine protected area $\cdot$ Fishery management

Resale or republication not permitted without written consent of the publisher

\section{INTRODUCTION}

Reliable, spatially explicit delineation of species/ habitat associations and their use in the accurate estimation of species distribution (both actual and potential) is essential for the implementation of effective ecosystem-based management strategies, particularly the design and monitoring of protected areas (i.e. reserves) (MacMahon 1997, Scott et al. 2002, Leathwick et al. 2008, Pittman et al. 2009). A variety of threats to marine ecosystems, including pollution, resource extraction and climate change, have contributed to significant decreases in distribution, abundance and health of organisms (Jackson et al. 2005, Dunn \& Halpin 2009). In response, marine spatial planning is being widely adopted as a more promising tool for effective marine conservation, including the implementation of marine protected areas (MPAs). However, successful implementation of MPAs requires accurate and detailed information on the habitat characteristics of importance to the species of interest (Pittman et al. 2007). 
Traditional methods of distributional estimates have typically relied upon broad extrapolation from narrowly constrained or sparse data sets, or very costly intense sampling efforts carried out over broad areas (Margules \& Austin 1991, Li \& Hilbert 2008). However, because the selection of habitats by organisms is nonrandom (Rhodes et al. 2005), habitat conditions important to the occurrence of a species can be used to predict their distribution and aid in the development of management plans (Fernandez et al. 2003).

In terrestrial environments, spatially explicit habitat suitability modeling has emerged as an efficient tool for generating accurate patterns and predictions of species abundance and distribution (Austin et al. 1994, Hirzel et al. 2002, Rotenberry et al. 2006, Kleinwachter \& Rickfelder 2007, Valavanis et al. 2008). The integration of recent advancements in GIS software (Hirzel et al. 2002, Rotenberry et al. 2006), spatial modeling tools (i.e. marine geospatial ecology tools, MGET), which use multivariate statistical models to associate species' occurrence with quantitative patterns in the landscape (Roberts et al. 2010), and broad-scale, high-resolution terrain mapping techniques now enable the creation of species-specific habitat suitability models over broad geographic ranges (Hirzel et al. 2002, Rotenberry et al. 2006, Valavanis et al. 2008). These models, e.g. generalized linear models (GLMs) and generalized additive models (GAMs), use information on species occurrence in relation to a number of environmental variables (e.g. elevation, slope, aspect, precipitation, temperature) to predict species occurrence in areas where no observational data on the presence or absence of those species exists (Rotenberry et al. 2006).

More recently, the use of habitat modeling as a technique to estimate species distributions has been implemented in the marine environment (i.e. Rubec et al. 1998, Lindholm et al. 2001, Nasby-Lucas et al. 2002, Auster et al. 2003, Bryan \& Metaxas 2007). However, the difficulty of sampling submerged habitats at sufficient scales and resolution has imposed limitations on the applicability of habitat models, and relatively few studies have analyzed the relationship between benthic habitat variables and the distribution and abundance of demersal fish species in deeper habitats (>30m) (Anderson \& Yoklavich 2007).

Along the west coast of North America, rockfish and other groundfish are the basis for broad-scale fisheries (Williams \& Ralston 2002, Anderson \& Yoklavich 2007). However, because these species are slow growing, long lived and require several years to reach reproductive maturity, they are highly vulnerable to overexploitation. Indeed, several of these species were harvested at unsustainable levels for many years and population sizes have been reduced to historic low levels (Williams \& Ralston 2002). Although there is a need for data on the distribution, abundance and habitat associations of the different species (Yoklavich et al. 1999, Williams \& Ralston 2002), there are limitations in the ability of several commonly employed field sampling techniques (e.g. trawling, SCUBA) to generate accurate estimates of distribution and abundance either regionally or over the broad geographic range of many rockfish species (Jagielo et al. 2003).

One method for acquiring visual observational data with spatial information that has become a standard method for quantifying rockfish is the use of a manned submersible (Jagielo et al. 2003). Yoklavich et al. (2007) used a submersible to conduct visual surveys of demersal juvenile and adult cowcod Sebastes levis over 8 major rocky banks in southern California and found assessments of cowcod are feasible using nonextractive visual methods to provide reasonable estimates of density, total abundance and biomass.

Although spatially referenced visual methods have become useful in quantifying the abundance of groundfish species, extrapolating those observations to areas where no visual data exist must be based upon predictions of the character of unobserved habitats. As a result, the ability to create predictions of species occurrence from high resolution in situ visual surveys could be greatly enhanced when integrated with broad-scale seafloor landscape models derived from high-resolution multibeam bathymetry and sidescan sonar data. Combining broad-scale, high-resolution habitat data with spatially restricted observational data allows for multiscale habitat-based community assessments. Recent advances in the acquisition and processing of bathymetric and backscatter data now enable the classification of seafloor habitats with spatial resolutions on the order of a few meters to upwards of hundreds of meters (Hughes Clarke et al. 1996, Nasby-Lucas et al. 2002). Species-specific habitat modeling based on remotely sensed seafloor geomorphology and texture data, as well as direct video fish survey data, should prove to be an efficient technique for defining essential fish habitat.

The purpose of this study was to determine how well spatial predictive modeling techniques traditionally used in terrestrial systems, such as GLMs, can be used to create species-specific habitat models that predict the distribution of demersal fishes over broad areas. We assumed that, because demersal species are associated with specific seafloor habitat types in the marine environment just as ground dwelling species are in terrestrial environments, it is likely that the methods used to successfully predict species distribution in terrestrial environments could be applied to marine systems. Using Cordell Bank and 3 species of rockfish - yellowtail rockfish Sebastes flavidus, rosy rockfish $S$. rosaceus, and greenstriped rockfish $S$. elongatus-as a 
model system, we created species-specific habitat suitability models using a combination of georeferenced video data and habitat parameters derived from highresolution topographic maps of Cordell Bank. The expectation was that predicted patterns of species distribution would correlate with actual observed species occurrence from video footage not used to parameterize the model. If successful, these types of models would be useful for helping to understand the relationships of species with their habitats and, in turn, could provide a tool for managers to characterize essential fish habitat, aiding in the implementation of marine spatial management and location of new MPAs.

\section{METHODS}

Natural history. The study site for this project is Cordell Bank, an $8 \times 15 \mathrm{~km}$ granitic formation located $40 \mathrm{~km}$ west of Point Reyes, California $\left(38.02^{\circ} \mathrm{N}\right.$, $123.44^{\circ} \mathrm{W}$ ), with pinnacles coming to within $40 \mathrm{~m}$ of the water's surface and surrounding depths being greater than $350 \mathrm{~m}$ (Fig. 1). The upwelling provided by the California Current makes Cordell Bank an area of high species abundance, supporting large populations of many resident and migratory species. Rockfishes Sebastes spp. are by far the most abundant resident fishes constituting $90 \%$ of the fish observed on the bank. Although the status of Cordell Bank as a National Marine Sanctuary does not protect it from fishing, the bank's remote location does appear to provide some refuge for rockfish species depleted elsewhere along the mainland, including boccacio $S$. paucipinis, yelloweye rockfish $S$. rubberimus, vermilion rockfish $S$. miniatus and canary rockfish $S$. pinniger (Anderson et al. 2009).

Data acquisition and processing. Multibeam and backscatter data were collected by the Seafloor Mapping Lab at California State University, Monterey Bay, aboard the RV 'VenTresca' at Cordell Bank National Marine Sanctuary, California, over a period of $8 \mathrm{~d}$ in

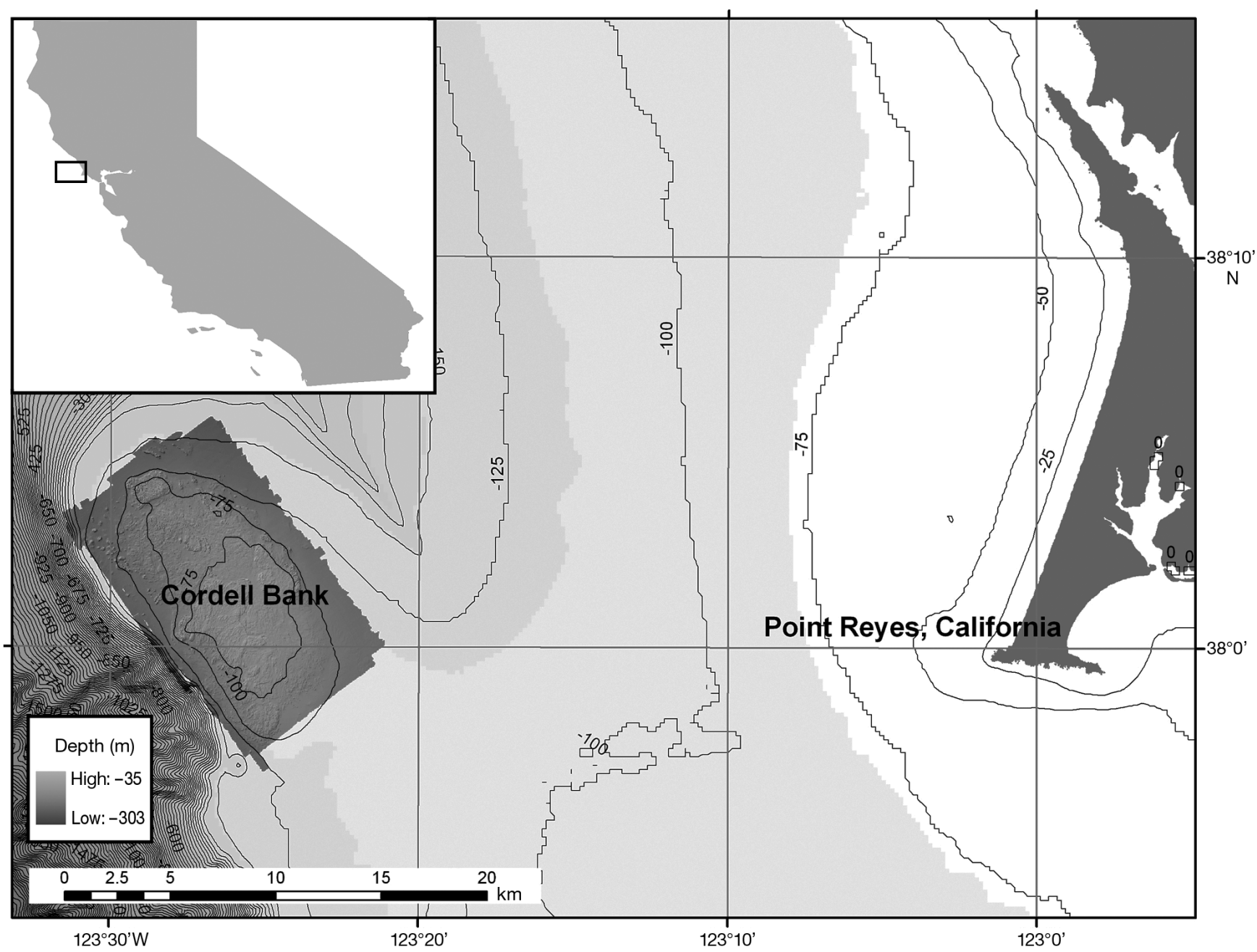

Fig. 1. Digital elevation model of Cordell Bank in relation to Point Reyes, California with $25 \mathrm{~m}$ depth contours created from the Department of Fish and Game $200 \mathrm{~m}$ statewide bathymetry. Depths are indicated with the shallower (high) white and the deeper (low) black 
September and October of 2005. A pole-mounted Reson SeaBat 8101 multibeam sonar was used. The multibeam sonar collects depth soundings at $1.5^{\circ}$ intervals across a $150^{\circ}$ swath. Data were recorded using an Isis Sonar data acquisition system (Triton Imaging 2005). Along with the sonar data, corrections for pitch, roll, heave and heading were collected using the Applanix Position and Orientation Systems for Marine Vessels (POS MV) system with $\pm 0.02^{\circ}$ accuracy. Vessel position data were provided by a C\&C Technologies CNav 2050 GPS Precise Point Positioning receiver enabled for Real Time GIPSY (RTG) corrections yielding horizontal and vertical accuracies of $0.15 \mathrm{~m}$ or better.

After acquisition, the multibeam data were imported into CARIS HIPS software where they were corrected for the effects of attitude, tide and sound velocity, and all erroneous data soundings were removed using standard hydrographic data cleaning procedures (CARIS 2006). After cleaning, the data were exported as XYZ (easting, northing, depth) data at regularly spaced $(3 \mathrm{~m})$ intervals from CARIS and, once verified that there were no spikes or erroneous soundings remaining, the data were exported as a digital elevation model (DEM) in Environmental Systems Research Institute (ESRI) grid format for GIS analysis. A DEM is a raster data set that consists of elevation values at regularly spaced intervals.

A comprehensive biological survey of Cordell Bank was conducted using the submersible vessel 'Delta' over 12 d in September and October of 2002. Sixty strip transects ( $2 \mathrm{~m}$ wide and $15 \mathrm{~min}$ in duration) were run across a variety of habitats ranging from 34 to $350 \mathrm{~m}$ in depth. During transects, the submersible remained within 1 to $2 \mathrm{~m}$ off the seafloor and traveled at speeds between 0.4 and 0.9 knots. All transects were videotaped with an externally mounted video camera, and the in situ observer's counts and descriptions were recorded and later transcribed in the laboratory. All fish within $2 \mathrm{~m}$ of the submersible were identified and counted. These presence/absence data were then converted into ESRI shapefile format for ArcGIS analysis.

Habitat analysis. GIS landscape analyses were performed on the DEM to delineate those habitats that many species of rockfish are known to prefer, including rocky areas with high relief or areas of large boulders and stones. Within ArcGIS 9 (ESRI 1999 to 2006), various tools were used to derive 4 habitat descriptor rasters from the DEM that would be used in the models to delineate these habitat types and predict the occurrence of rockfish on Cordell Bank: these were depth, slope, aspect, vector ruggedness and topographic position index (TPI) rasters (Fig. 2). The correlation of the habitat variables was explored before choosing variables for the models so that 2 correlated variables were not used in the same model.
Depth information for Cordell Bank was provided by the DEM. Depth is believed to be the single most important predictor of rockfish distribution (Williams \& Ralston 2002, Anderson \& Yoklavich 2007). Many species of rockfish are associated with specific depth ranges and most species increase in abundance with increasing depth up to 250 m (Williams \& Ralston 2002).

Slope and aspect rasters were derived from the bathymetric DEM using the ArcGIS Spatial Analyst extension. Slope values were expected to serve as good predictors of fish presence or absence because areas of high slope are believed to be associated with consistently greater densities of fish than less sloping areas (McClatchie et al. 1997). Aspect, or the compass direction that a slope faces, was chosen as a potential predictor of rockfish abundance because the aspect of the slope relative to prevailing ocean current direction may influence food availability, recruitment and habitat suitability.

Vector ruggedness measure (VRM) grids were created using the Terrain Tools toolbox for ArcGIS (Sappington et al. 2007). Vector ruggedness is a measure of the terrain ruggedness using vector analysis where the 3-dimensional orientation of the grid cells are taken into account, allowing for variation in slope and aspect (Hobson 1972). Flat smooth areas have VRM values near 0 , while the higher values (up to 1) are associated with areas of higher relief or bumpiness. Vector ruggedness is an appropriate parameter for predicting the distribution of rockfish because it captures the topographic complexity of the habitat. Topographic complexity is an important habitat characteristic that serves many ecological roles (i.e. often correlated with species richness and provides refuge from predators and physical stress) (Pittman et al. 2007, Zawada \& Brock 2009) that could be of importance to the distribution of rockfish species. Previous studies have shown that there is a strong relationship between topographic complexity and reef fish abundance (Friedlander \& Parrish 1998, Walker et al. 2009) because greater complexity is correlated with an increase in substratum and the availability of refuge (MacArthur \& Levins 1964, Pittman et al. 2007).

From the VRM map, a 'distance to rock' raster was derived. The study area was classified into 'rock' and 'soft sediment' by choosing a cutoff value in the VRM of 0.001 and reclassifying the map. This cutoff value was chosen through trial and error and found to be the optimal value because it adequately separated the areas into the different substrate types. After classifying the map into rock and soft sediment, the raster was converted to polygons. From the polygons, the Euclidean distance tool was used to extrapolate out a distance-to-rock value for the entire extents of the study area. Distance to rock was expected to be a good predictor of the distribution of rockfish because, al- 

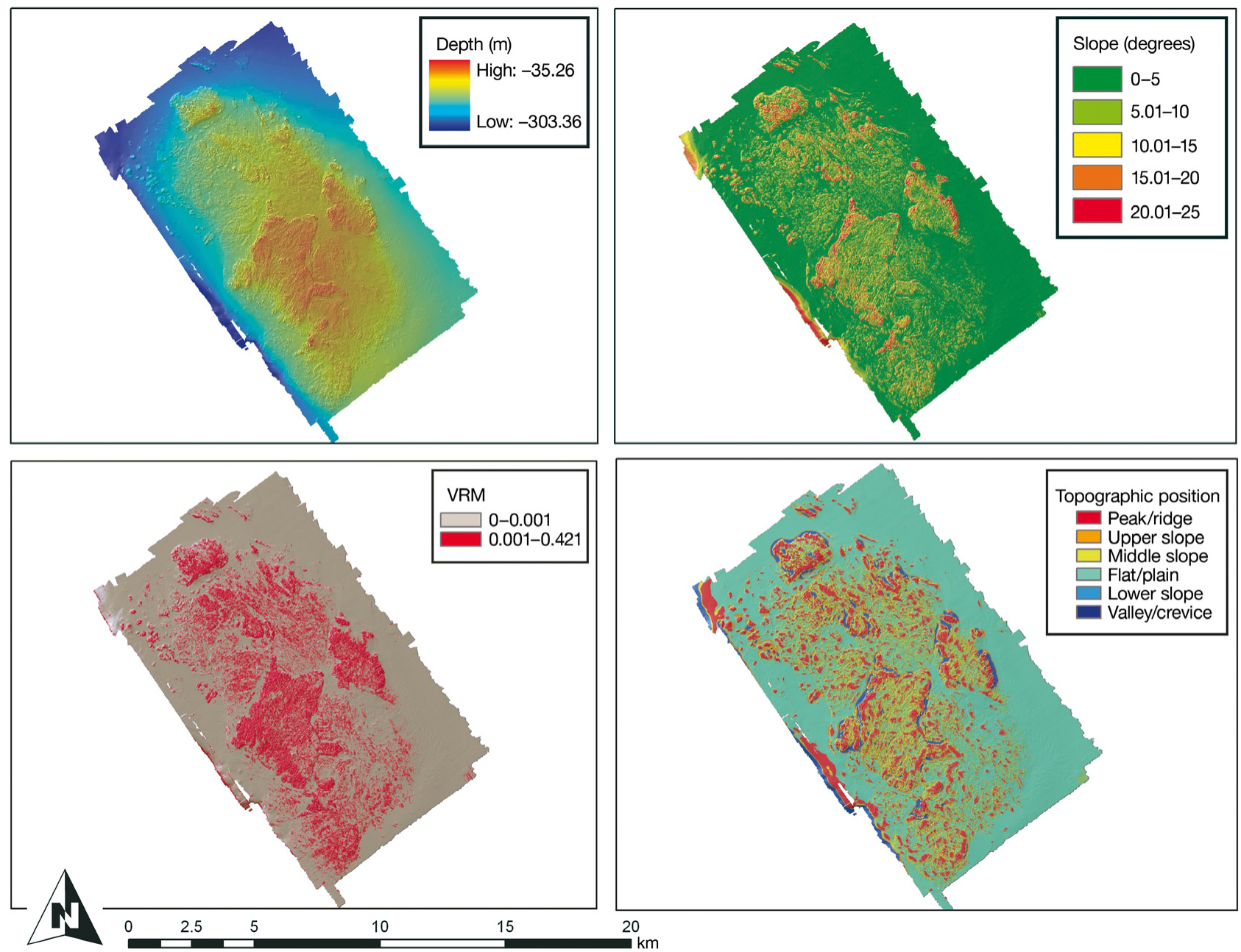

Fig. 2. Habitat metrics derived from the multibeam bathymetry DEM at Cordell Bank. Depth, slope, VRM and broad scale TPI are shown. These habitat parameters were used in GLM predictions of rockfish habitat suitability (probability of occurrence). DEM: digital elevation model; TPI: topographic position index; VRM: vector ruggedness measure

though they may not be found directly above a rock feature, they are usually found in close proximity (Iampietro et al. 2005).

The final habitat metric derived was topographic position index (TPI), which indicates the position of a given point relative to the overall surrounding landscape (Lundblad et al. 2006). TPI can be used to delineate landforms such as peaks, ridges, cliffs, slopes, flat plains and valleys, and is calculated by comparing the elevation of each cell in a DEM to that of its surroundings. Because the neighborhood size of the surroundings used for the elevation comparison can be adjusted, TPI can be calculated at various scales. Thus, an analysis size can be chosen that will identify features of any desired size, ranging from fine-scale features such as the tops of boulders and pinnacles, to entire reefs, to regional-scale features such as seamounts. Likewise, TPI can be used to locate fissures and cracks in rock, sand channels and submarine can- yons (Lundblad et al. 2006). The TPI analysis employed in this study was done using the algorithm of Weiss (2001), which uses an annulus ('donut') shaped neighborhood. TPI products were created using the bathymetric position index (BPI) grid creation and classification tools included in the BTM to create grids with scales of analysis at 30,60, 120 and $240 \mathrm{~m}$ (orad), with an arbitrary 5 cell $(15 \mathrm{~m})$ annulus thickness (oradirad). A variety of scales were chosen to determine whether rockfish are more closely associated with broad, fine or medium scale features (Fig. 2).

GLMs. The three species of rockfish chosen for this analysis, Sebastes flavidus, S. elongatus and S. rosace$u s$, were selected based on the types of habitat in which they are commonly found and because they are commercially and economically important. S. flavidus and $S$. rosaceus are commonly found in high-relief rocky habitats while $S$. elongatus is found in low-relief muddy habitats (Love et al. 2002). The presence and 
absence observation points for each species of interest were derived from the video data. The spatially explicit observations of the species of interest along transects were used as the presence points and the points along transects, where the species was not seen were used as the absence points.

The absence points were further subsampled to reduce the number of potential 'false absences,' using a 2-step approach similar to the one outlined by Engler et al. (2004). Using this approach, an ecological niche factor analysis (ENFA) model (Hirzel et al. 2002) is created from presence only data and then that model is used to determine the locations of absence data. To create the ENFA model, the BioMapper software application was used along with the habitat maps and the species presence data to create species-specific habitat suitability maps. Rather than creating pseudoabsences as described by Engler et al. (2004), the observational survey of Cordell Bank was extensive enough to allow us to subsample the absence data from the transects by selecting only those absences found in the unsuitable habitat identified by the ENFA model. Using this approach reduces the risk of including false absences in the model, which can bias the results (Hirzel et al. 2002).

The presence and absence points were separated into training and evaluation data sets. Seventy percent of the presence and absence points were randomly selected for use in the training of the models while the remaining $30 \%$ were set aside as the 'observed' data set for evaluating the accuracy of model predictions. The absence data were also derived from the biological observation data. Points along transects where the species of interest was not observed were treated as absence points. The absence data were also dividedinto training $(70 \%)$ and evaluation $(30 \%)$ data sets.

The presence and absence point location shapefiles were used together with the DEM and derived habitat parameter rasters in ArcGIS to create predictive models using the Marine Geospatial Ecology Toolbox (MGET) (Roberts et al. 2010). MGET integrates ArcGIS with the R statistical package (R Development Core Team 2007) to produce multivariate habitat prediction rasters. Within this toolbox, the GLM tool was used to produce predictive grids for each species of rockfish based on their associations with the habitat on which they were found. GLMs are believed to be good tools for analyzing ecological relationships because they do not force the data into unnatural scales. GLMs do not require the data to be linear or have constant variance and they are capable of using data from a number of different probability distributions (Guisan et al. 2002).

The GLM within MGET samples the values of each of the predictor rasters (e.g. slope, rugosity, depth) at each presence and absence point location and then uses those data to create prediction rasters that display the probability of species occurrence for unsampled locations using a binomial logistic regression model (Guisan et al. 2002). A stepwise Akaike's information criterion (AIC) analysis selects the coefficients to determine the best fit model (Posada \& Buckley 2004).

The GLM analyses were performed using the fish presence/absence and habitat raster data for each species separately, with the same general methods applied to each species. Each time the MGET GLM tool was used, the appropriate fish presence/absence point locations were specified along with the habitat parameter rasters of interest. These rasters included the bathymetric DEM and derived parameters such as aspect, slope, VRM and TPI at the broad and fine scale levels. Because results from preliminary models suggested that VRM and slope were correlated, these variables were not used together in any of the models. Separate models containing either VRM or slope were tested to determine which model was a more effective predictor of fish distribution in each case and the best model was then chosen for analysis. The GLM tool produces a predictive map of species occurrence based on the model and input raster layers, which is converted to ArcGIS format for visualization and further analysis. Once completed, each of the models was tested for their predictive capabilities by comparing the predicted occurrence of fish to the observed presence and absence points (the $30 \%$ of the observational data set aside for model evaluation and not used in the creation of the model).

Model validation. To test model accuracy, Cohen's Kappa values were calculated for each of the speciesspecific models to determine the agreement between the predicted and observed presence and absence values. Cohen's Kappa is a statistical test that measures the agreement between categorical terms. It is similar to percent agreement but is more robust in that it takes into account agreement occurring by chance (Cohen 1960). A binary predicted presence/absence raster was derived from the probability of occurrence raster for each species by setting a threshold probability of 0.6. This value was chosen because it is within the range of 0.5 to 0.7 , which is commonly used in published GLM studies (Austin 1998, Hirzel \& Guisan 2002). The cell values in the binary predicted presence/absence raster for each species were thus ' 0 ' wherever the GLM predicted the probability of occurrence to be less than 0.6 , and ' 1 ' in locations where that threshold was exceeded. The observed presence/ absence locations for each species that were reserved and not used in model fitting were compared with the respective predicted presence/absence raster cell values, and the agreement between the 2 was quantified using Cohen's Kappa analysis. 
Spatial autocorrelation. To further test the strength of these models, the data were tested for spatial autocorrelation (SA), which is a common property of ecological variables where observations at specific geographic distances apart are more similar to each other or less similar than would be expected by random chance (Legendre 1993). It is most likely to occur when observations are closely spaced rather than being more widely separated in space and often results in an increase in Type I errors or false positives (Segurado et al. 2006), thereby reducing the explanatory and predictive value of species distribution models (Segurado et al. 2006). Thus, if SA is present in the response variable, the explanatory variables have exaggerated significance and the coefficients of these variables are inflated.

A basic assumption of GLMs is independence in the residual errors (McCullagh \& Nelder 1989, Wintle \& Bardos 2006). However, if SA is significant and not taken into account when developing species distribution models based on GLMs, that basic assumption is not met. Therefore, the predictions could be biased and the predictive power of the model diminished (Wintle \& Bardos 2006). Furthermore, when creating predictive models with spatially autocorrelated explanatory variables, the significance attributed to more spatially autocorrelated variables may be exaggerated. The bias towards the more autocorrelated variables has the potential to leave out less autocorrelated variables, which could be more important to the presence of the species of interest than are the autocorrelated variables selected for the model (Segurado et al. 2006).

The R statistical package was used to generate spatial correlograms using Moran's I coefficients to test whether the GLMs used in this study were influenced by SA. In particular, the spatial locations of the fish presence/absence points used to create the model (the response variables) were tested against the habitat parameters for the occurrence of SA. Moran's I measures how similar samples of a given variable are over varying spatial distances and usually ranges from -1.0 to 1.0, where negative values represent negative spatial autocorrelation and positive values represent positive spatial autocorrelation. A Moran's $I$ value of ' 0 ' indicates no spatial autocorrelation. After creating the correlograms, an ANOVA was used to determine whether the observed spatial autocorrelation was significant.

Comparison between GLMs and autologistic regression (ALR). If significant spatial autocorrelation was found, an ALR model was run on the response variables to determine whether there was a significant change in the explanatory power of the model coefficients (Legendre 1993, Dormann 2007). ALR takes into account the spatial variation of the data by including autocovariance as an additional explanatory variable in the model (Dormann 2007). The ALR was run in $\mathrm{R}$ using autocovariate regression in the 'spdep' package. The results of the ALR were then compared with those of the GLM to determine whether the explanatory power of the models was lost.

\section{RESULTS}

\section{Model accuracies}

As expected, the GLM for Sebastes flavidus predicted the highest probability of occurrence in rocky high-relief habitats and lower probability in low-relief, soft sediment habitats (Fig. 3).

Comparison of the evaluation data set to model predictions resulted in $69 \%$ agreement for presence and $97 \%$ for absence locations. The overall accuracy of the model was $92 \%$ with a statistically significant Cohen's Kappa (KHAT) value of 0.714 ( $\mathrm{p}<0.000)$. A KHAT value between 0.61 and 0.80 signifies a 'substantial' agreement (Landis \& Koch 1977). Stepwise AIC analysis found depth, depth ${ }^{2}$, distance to rock, and $30 \mathrm{~m}$ TPI to be significant factors in predicting the distribution of Sebastes flavidus (Table 1). The equation for the model based on the coefficients is:

$$
\begin{aligned}
& \text { GLM }=6.864+\left[\left(1.249 \mathrm{e}^{-1}\right) \times \text { depth }\right]+ \\
& {\left[\left(4.187 \mathrm{e}^{-4}\right) \times(\text { depth })^{2}\right]-\left[\left(1.510 \mathrm{e}^{-2}\right) \times \text { distance to rock }\right]+} \\
& {\left[\left(6.391 \mathrm{e}^{-1}\right) \times \text { TPI } 30 \mathrm{~m}\right]}
\end{aligned}
$$

Again, as expected, the models for Sebastes rosaceus found the highest probabilities of occurrence in the rocky high-relief habitats whereas the flat, soft sediment habitats had low values (Fig. 4). The prediction accuracies for $S$. rosaceus were even higher than those for $S$. flavidus, with presence and absence predicted correctly 99 and $96 \%$ of the time, respectively. The overall accuracy of the model was $96 \%$ with a statistically significant KHAT value of 0.886 ( $p<0.000)$. The KHAT value of 0.886 signifies 'almost perfect' agreement between the evaluation data set and the predictions (Landis \& Koch 1977). The stepwise AIC analysis for $S$. rosaceus found depth ${ }^{2}$, slope ${ }^{2}$, VRM and distance to rock to be the most significant factors in predicting the distribution of this species (Table 2). The equation for the model based on the coefficients is:

$$
\begin{aligned}
& \mathrm{GLM}=4.365-\left[\left(4.939 \mathrm{e}^{-4}\right) \times(\text { depth })^{2}\right]- \\
& {\left[\left(2.321 \mathrm{e}^{-3}\right) \times(\text { slope })^{2}\right]-[(163.4) \times \mathrm{VRM}]+} \\
& {\left[\left(5.503 \mathrm{e}^{-3}\right) \times \text { distance to rock }\right]}
\end{aligned}
$$

Unlike the GLMs for Sebastes flavidus and S. rosaceus, the GLM for $S$. elongatus predicted the highest probability of occurrence in the deep and flat soft sedi- 


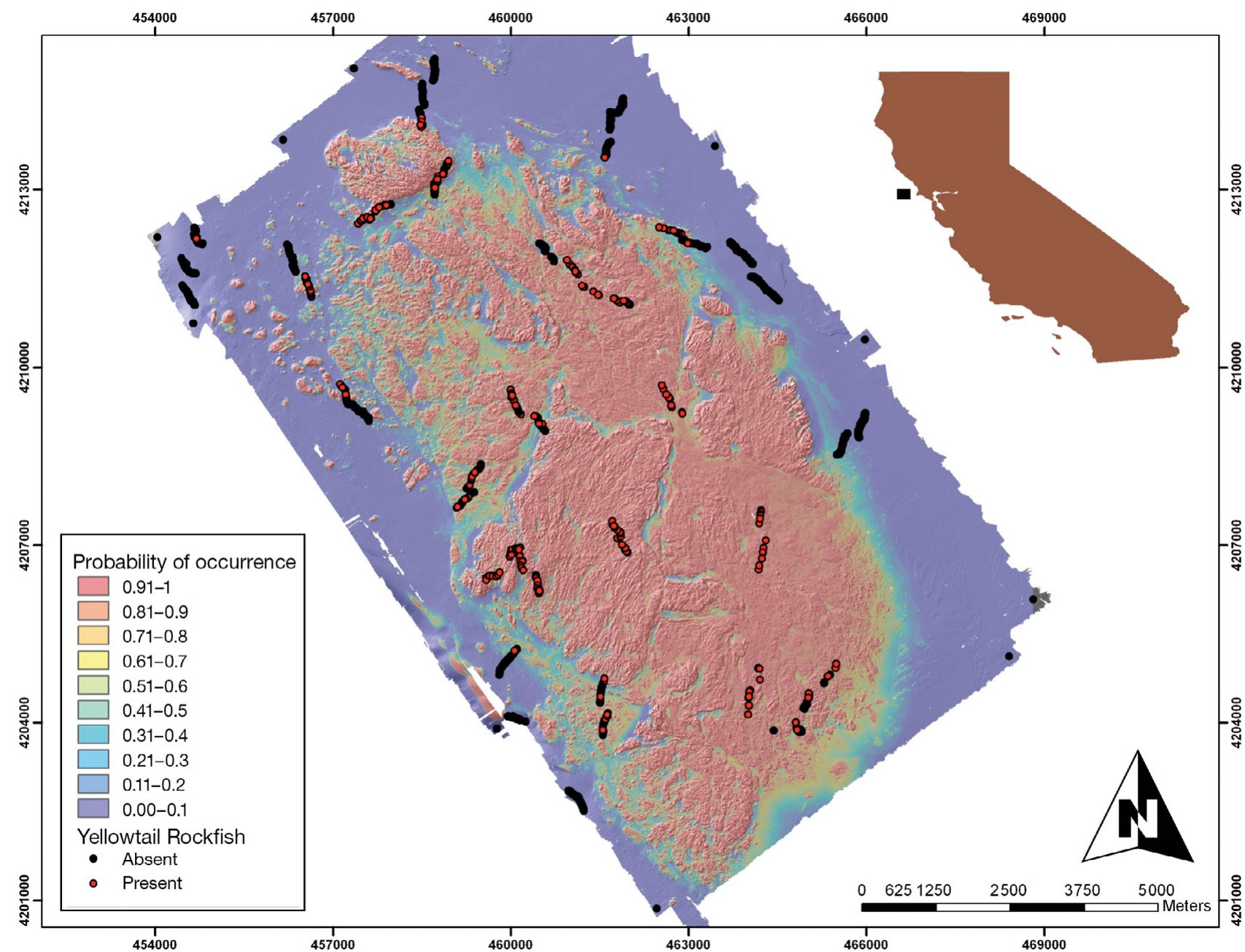

Fig. 3. Sebastes flavidus. GLM results for yellowtail rockfish. Reddish (bluish) colors indicate highest (lowest) predicted probability of occurrence for $S$. flavidus. Red dots signify locations where $S$. flavidus were observed, while black dots indicate areas where they were absent. Grid reference system in WGS 1984, UTM zone 10N

ment areas (Fig. 5). Presence was predicted correctly $60 \%$ of the time and absence was predicted correctly $97 \%$ of the time. The overall accuracy of the model was $92 \%$ with a statistically significant KHAT value of $0.621(\mathrm{p}<0.000)$. A KHAT value between 0.61 and 0.80 signifies a 'substantial' agreement (Landis \& Koch 1977). The stepwise AIC analysis for this GLM found depth, VRM and $240 \mathrm{~m}$ TPI to be significant factors for predicting the distribution of $S$. elongatus (Table 3). The equation for the model based on the coefficients is:

GLM $=-23.830-\left[\left(2.872 \mathrm{e}^{-1}\right) \times\right.$ depth $]-$ $\left[\left(6.658 \mathrm{e}^{-4}\right) \times(\text { depth })^{2}\right]-(4416 \times$ VRM $)+$ $\left[\left(-3.632 \mathrm{e}^{-3}\right) \times\right.$ distance to rock $]-\left[\left(6.175 \mathrm{e}^{-3}\right) \times\right.$ TPI240]
Table 1. Comparison of the coefficients and significance ( $p$-values) of each of the habitat parameters used in the GLM and autologistic regression (ALR) models for Sebastes flavidus. Asterisks ( ${ }^{*}$ ) indicate the p-value is significant based on an $\alpha$ of 0.05 . na: not applicable

\begin{tabular}{|c|c|c|c|c|}
\hline \multirow[t]{2}{*}{ Parameter } & \multicolumn{2}{|c|}{ Model coefficient } & \multicolumn{2}{|c|}{ p-value } \\
\hline & GLM & ALR & GLM & ALR \\
\hline Intercept & 6.864 & 2.281 & $<0.000^{*}$ & 0.370 \\
\hline Depth & $1.249 \mathrm{e}^{-1}$ & $1.993 \mathrm{e}^{-2}$ & $<0.000^{*}$ & 0.710 \\
\hline Depth $^{2}$ & $4.187 \mathrm{e}^{-4}$ & $-2.620 \mathrm{e}^{-4}$ & $0.008^{*}$ & 0.336 \\
\hline Distance to rock & $-1.510 \mathrm{e}^{-2}$ & $-2.769 \mathrm{e}^{-3}$ & $<0.000^{*}$ & 0.094 \\
\hline TPI $30 \mathrm{~m}$ & $6.391 \mathrm{e}^{-1}$ & $5.072 \mathrm{e}^{-1}$ & $<0.000^{*}$ & 0.081 \\
\hline Autocovariance & na & 21.312 & na & $<0.000^{*}$ \\
\hline
\end{tabular}

\section{Spatial autocorrelation}

Spatial autocorrelation was significant for all variables except slope and aspect in the models for Sebas- 


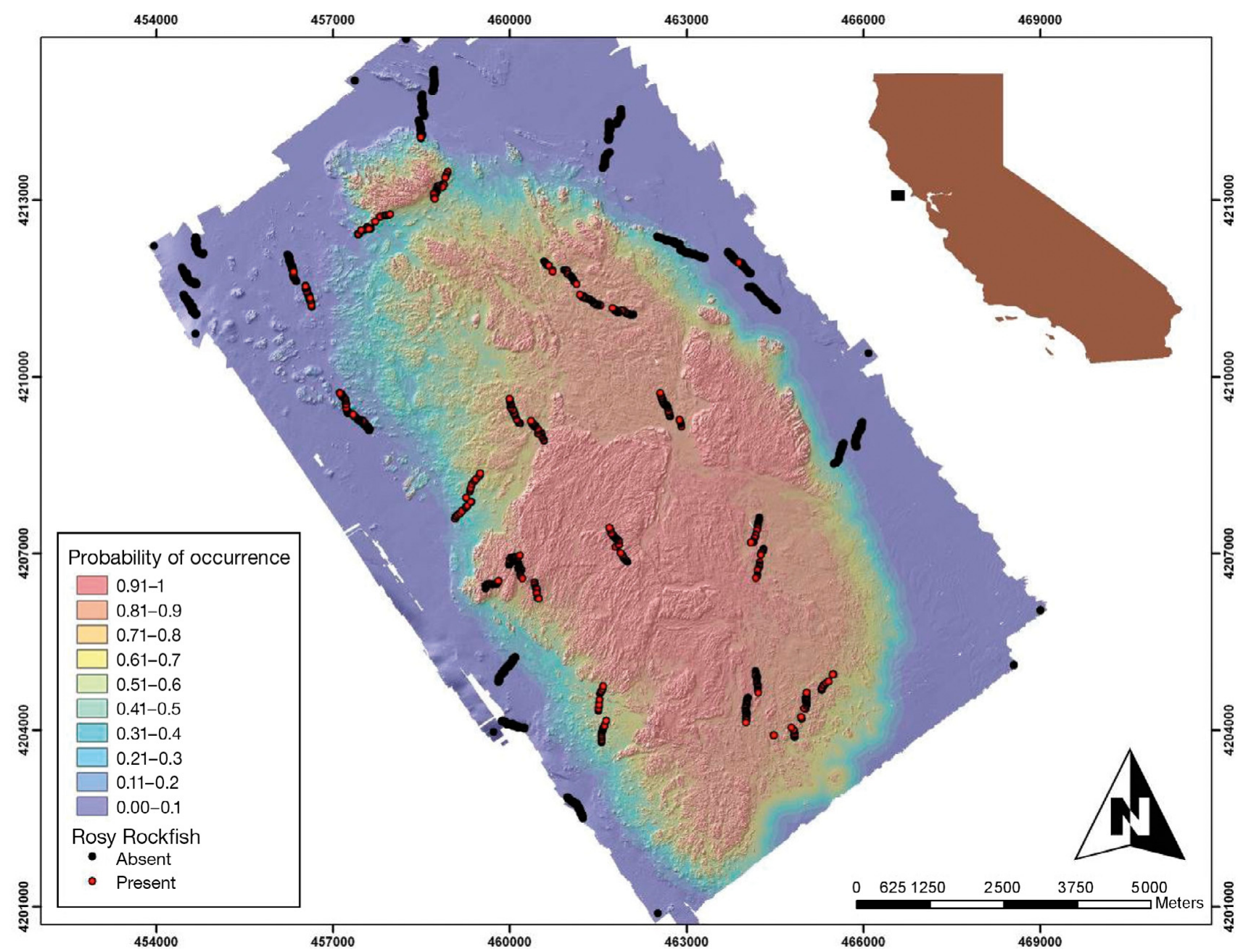

Fig. 4. Sebastes rosaceus. GLM results for rosy rockfish. Reddish (bluish) colors indicate highest (lowest) predicted probability of occurrence for $S$. rosaceus. Red dots signify locations where $S$. rosaceus were observed, while black dots indicate areas where they were absent. Grid reference system in WGS 1984, UTM zone 10N

Table 2. Comparison of the coefficients and significance (p-values) of each of the habitat parameters used in the GLM and autologistic regression (ALR) models for Sebastes rosaceus. Asterisks (*) indicate the p-value is significant based on an $\alpha$ of 0.05. na: not applicable

\begin{tabular}{|c|c|c|c|c|}
\hline \multirow{2}{*}{ Parameter } & \multicolumn{2}{|c|}{ Model coefficient } & \multicolumn{2}{|c|}{ p-value } \\
\hline & GLM & ALR & GLM & ALR \\
\hline Intercept & 4.365 & 5.357 & $<0.000^{*}$ & $<0.000^{*}$ \\
\hline Depth $^{2}$ & $-4.939 \mathrm{e}^{-4}$ & $-7.391 \mathrm{e}^{-4}$ & $<0.000^{*}$ & $0.002^{*}$ \\
\hline Slope $^{2}$ & $-2.321 \mathrm{e}^{-3}$ & $1.321 \mathrm{e}^{-2}$ & $0.010^{*}$ & 0.775 \\
\hline VRM & 163.400 & -26.060 & 0.579 & $0.044^{*}$ \\
\hline Distance to rock & $-5.503 \mathrm{e}^{-3}$ & $-7.386 \mathrm{e}^{-3}$ & $0.002^{*}$ & $<0.000^{*}$ \\
\hline Autocovariance & na & 14.970 & na & $<0.000^{*}$ \\
\hline
\end{tabular}

tes rosaceus and $S$. elongatus, respectively. The spatial correlograms for the residuals of the variables for all 3 species showed a pattern of positive autocorrelation of all the variables at finer scales with a decrease in
Moran's I values up to approximately $500 \mathrm{~m}$, beyond which the Moran's I coefficients fluctuate around zero between negative and positive autocorrelation as the scale increases. These results suggest that the predictor variables have a patchy distribution at the finer spatial scales and a more random distribution as the spatial scale increases. The same pattern was seen among the predictor variables for all 3 species (Fig. 6).

After determining that there was significant spatial autocorrelation, ALR was run on the response variables to determine whether accounting for autocovariance reduced the effect of spatial autocorrelation and, therefore, improved the accuracy of the models. The results from 


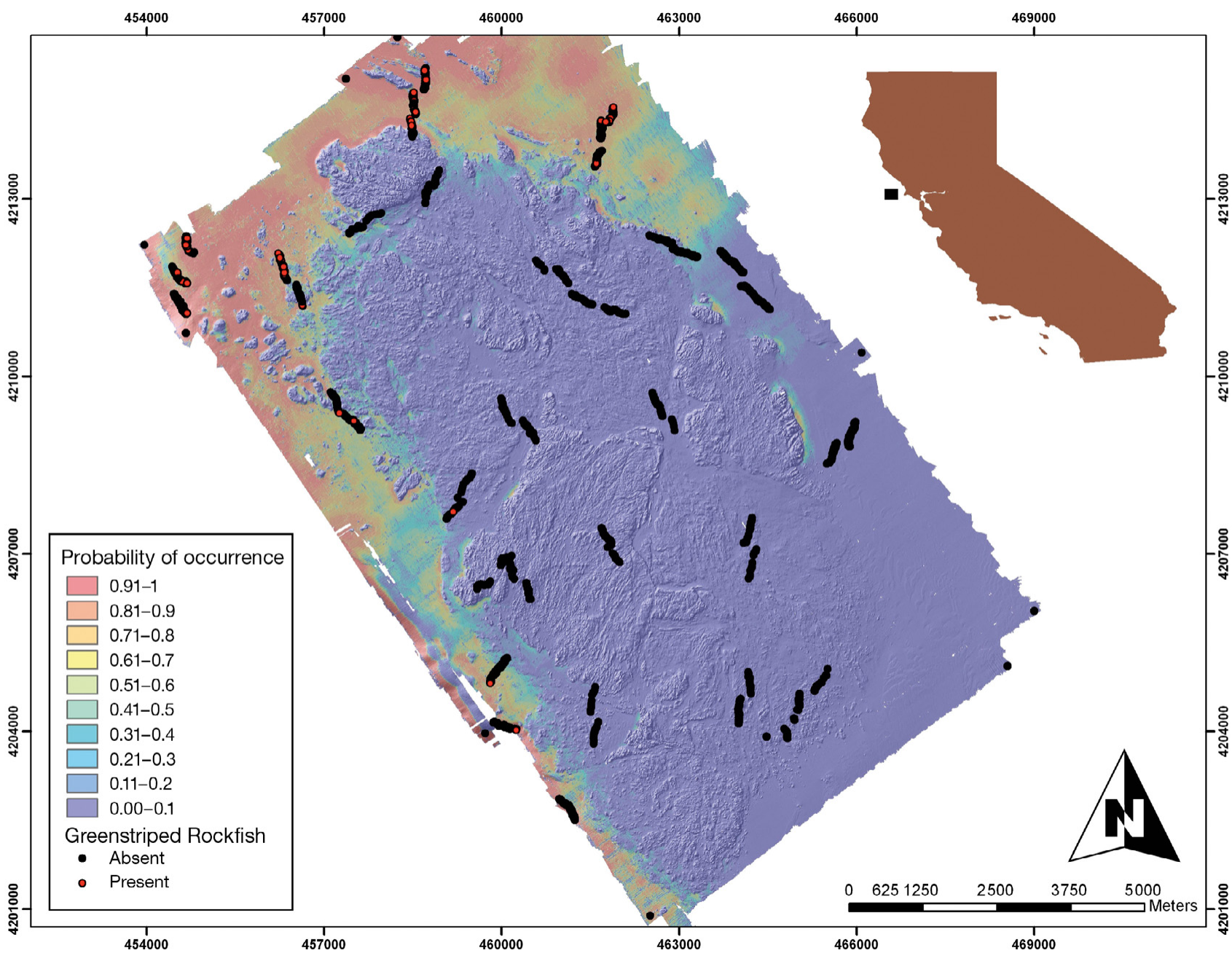

Fig. 5. Sebastes elongatus. GLM results for greenstriped rockfish. Reddish (bluish) colors indicate highest (lowest) predicted probability of occurrence for $S$. elongatus. Red dots signify locations where $S$. elongatus were observed, while black dots indicate areas where they were absent. Grid reference system in WGS 1984, UTM zone 10N

Table 3. Comparison of the coefficients and significance (p-values) of each of the habitat parameters used in the GLM and autologistic regression (ALR) modelsfor Sebastes elongatus. Asterisks $\left({ }^{*}\right)$ indicate the p-value is significant based on an $\alpha$ of 0.05 . na: not applicable

\begin{tabular}{|lcccc|}
\hline \multirow{2}{*}{ Parameter } & \multicolumn{2}{c}{ Model coefficient } & \multicolumn{2}{c|}{ p-value } \\
& GLM & ALR & GLM & ALR \\
\hline Intercept & -23.830 & -23.810 & $0.014^{*}$ & \multirow{2}{*}{$0.014^{*}$} \\
Depth & $-2.872 \mathrm{e}^{-1}$ & $-2.870 \mathrm{e}^{-1}$ & $0.053^{*}$ & $0.054^{*}$ \\
Depth & & $-6.649 \mathrm{e}^{-4}$ & 0.245 & 0.257 \\
VRM & $-6.658 \mathrm{e}^{-4}$ & -4419 & $0.020^{*}$ & $0.021^{*}$ \\
Distance to rock & $-4.632 \mathrm{e}^{-3}$ & $-3.638 \mathrm{e}^{-3}$ & 0.344 & 0.345 \\
TPI 240 m & $-6.175 \mathrm{e}^{-1}$ & $-6.167 \mathrm{e}^{-1}$ & $0.038^{*}$ & $0.040^{*}$ \\
Autocovariance & na & $4.278 \mathrm{e}^{-2}$ & na & 0.985 \\
& & & & \\
\hline
\end{tabular}

rosaceus. For S. elongatus, the level of spatial autocorrelation was very similar whether autocovariance was included as a term in the model or not (Fig. 6).

\section{Comparison of GLM and ALR models}

The GLM and ALR models differed for Sebastes flavidus and S. rosaceus but remained similar for $S$. elongatus. For S. flavidus, all the variables found to be significant in the GLM became insignificant when autocovariance was

the ALR showed that, although spatial autocorrelation was reduced at the finer scales, the reduction was not substantial and it did not completely eliminate the spatial autocorrelation for Sebastes flavidus and $S$. included as a term in the ALR model. Distance to rock and the $30 \mathrm{~m}$ TPI were nearly significant, but only the autocovariance term was found to be a significant predictor in the ALR (Table 1). 

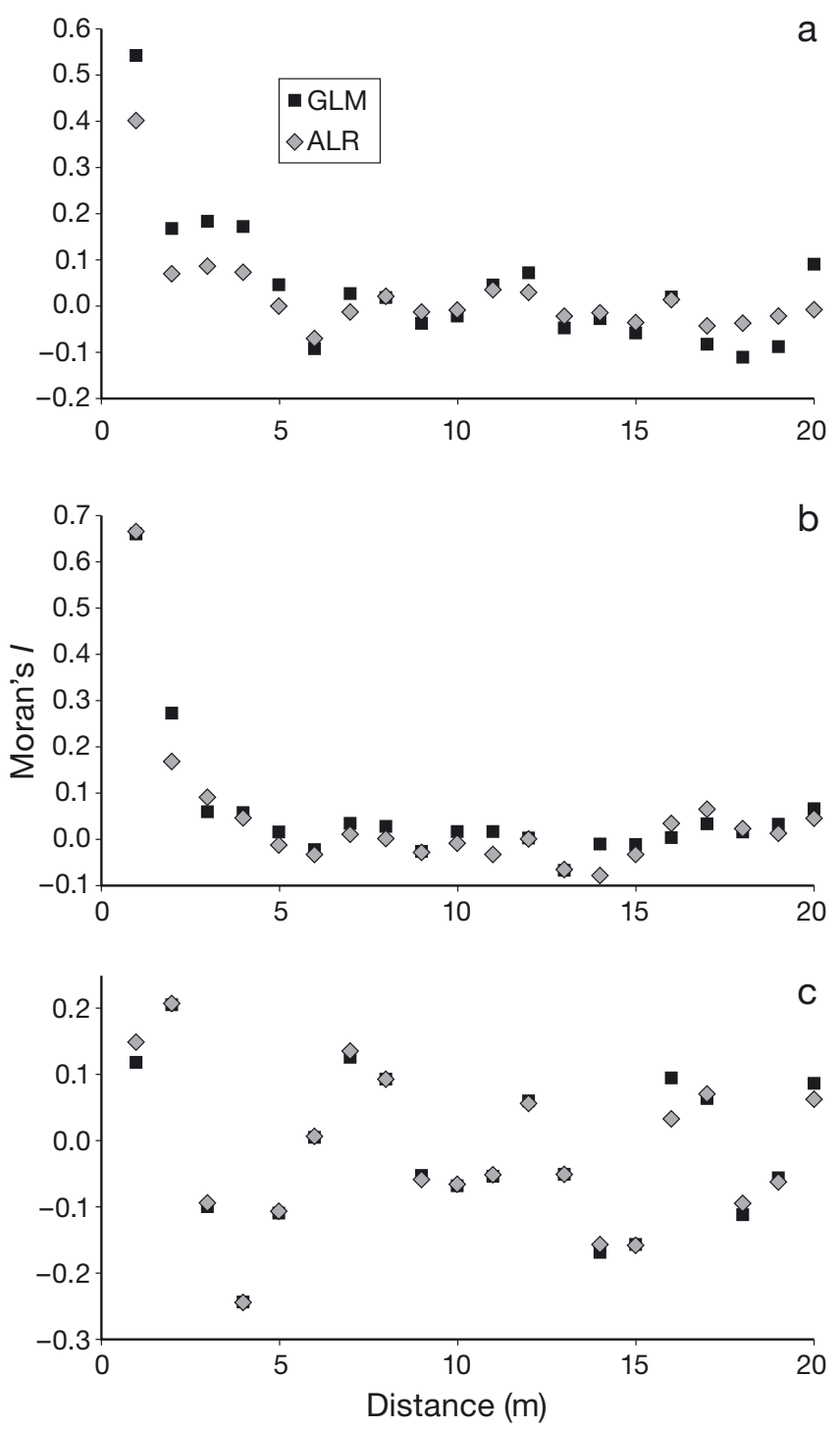

Fig. 6. Spatial correlograms for the presence of (a) Sebastes flavidus, (b) S. rosaceus and (c) S. elongatus. The black squares are from the correlograms created from the GLM and the gray diamonds are from the spatial correlograms created from the autologistic regression (ALR). These spatial correlograms show that the ALR decreases the spatial autocorrelation slightly but does not eliminate it completely for any of the species

The difference between the GLM and ALR was less significant for Sebastes rosaceus. All variables found to be significant in the GLM remained significant in the ALR except for slope ${ }^{2}$, which became insignificant. In addition, the autocovariance term became significant in the ALR (Table 2).

In contrast to the other 2 species, the GLM and ALR for Sebastes elongatus remained very similar. All the coefficients remained similar and the significance of the variables changed by only a negligible amount (Table 3).

\section{DISCUSSION}

\section{Evaluation of modeling methods}

The application of GLMs to high-resolution seafloor terrain data proved to be a highly efficient and effective method for creating accurate, species-specific habitat maps for those rockfish species at Cordell Bank. Previous studies have shown that rockfish prefer sloping terrain (McClatchie et al. 1997) and it is clear from these results that Cordell Bank offers a substantial amount of potential habitat with the majority of the bank classified as sloping.

In addition, the VRM analysis gives information on the amount of available rocky substrate. Because slope and VRM are correlated, the stronger predictor of fish presence/absence was used as a predictor in the models. As shown in other studies (MacArthur \& Levins 1964, Friedlander \& Parrish 1998, Dunn \& Halpin 2009, Walker et al. 2009), the complexity of the habitat (VRM) was found to be an important predictor of occurrence for both Sebastes rosaceus and S. elongatus.

In all the models, either depth ${ }^{2}$ or a combination of depth and depth ${ }^{2}$ were important variables for explaining the distribution of the 3 species of rockfish used in this study. This result is consistent with other studies in which both the abundance and number of rockfish species increase with depth between 151 and $250 \mathrm{~m}$ and then decrease below this range (Williams \& Ralston 2002). The polynomial function captured the nonlinear relationship between rockfish and depth and helped in accurately predicting their distribution. Although depth proved to be an important predictor, when used alone it does not fully explain the distribution of fish.

The TPI analyses showed the difference in habitat types when analyzed at differing scales. The fine scale analyses had fewer habitat classes than did the broad scale and the habitat patches were much smaller. When included in the models, Sebastes flavidus was closely associated with the fine-scale habitats while $S$. elongatus was more closely associated with the broadscale habitats. Depending on the species of fish, either broad or fine scale TPI might better explain and predict a species distribution. Regardless of scale, the TPI analysis does capture features that are important to the distribution of species, which is similar to results from other studies (Weiss 2001, Lundblad et al. 2006).

Distance to rock was a significant predictor for the occurrence of Sebastes flavidus and S. rosaceus found in the high-relief rocky habitats. Although these species may not be found directly on top of the rocky habitat, they are found in close proximity to it. This result agrees with those found in other studies where proximity to peaks was found to be a good predictor of rockfish occurrence (Iampietro et al. 2005). 
GLMs based on seafloor geomorphology were effective at predicting the probability of occurrence for all the species used in this study. However, the model for Sebastes elongatus classified all the flat, deep sediment areas as high probability of occurrence. This result could cause an over-estimation of suitable habitat for this species. Given the bathymetry-derived variables used (depth, VRM, slope, TPI and distance to rock, the models were able to discriminate between different rocky habitats more effectively than between the subtle differences in the muddy habitat preferences of $S$. elongatus. The acoustic backscatter (i.e. sidescan sonar) collected with the multibeam bathymetry data can be used in the discrimination of finscale seafloor texture such as sediment types, and its inclusion in the analysis would probably yield a much better and more detailed landscape model of $S$. elongatus probabilities of occurrence. Unfortunately, backscatter data could not be included in the GLMs used here because there were too many unique values ( $\mathrm{n}=$ 256) in the raw, unclassified, side scan mosaics, causing the models to crash due to limitations in computer processing power. One possible solution would be to use classified backscatter intensity as described by Cochrane \& Lafferty (2002) and Intelmann \& Cochrane (2006), thereby reducing the number of substrate texture classes to a more manageable range.

Another potential flaw with the Sebastes elongatus model could be the small number of observations recorded for this species. Although not applied here, different methods, such as ordination, may be more suitable in situations where very few presence points exist. This method is based on reciprocal averaging of species and site scores and is better at dealing with data that have many absences or zeroes (Guisan \& Zimmermann 2000).

\section{Spatial autocorrelation}

The analysis of spatial autocorrelation revealed that all variables were spatially autocorrelated, especially at the finer spatial scales. All of the variables followed the same general pattern with positive spatial autocorrelation at the finer scales and then fluctuations between positive and negative spatial autocorrelation. This pattern shows that these 3 species of rockfish and the variables they are associated with have a patchy distribution up to about $500 \mathrm{~m}$ and then a more random distribution at the larger spatial scales, which shows that rockfish are associated with certain types of habitats and are not found randomly throughout Cordell Bank.

Although, in the past, spatial autocorrelation in ecological data was believed to inflate Type I errors and increase bias in statistical analyses, new studies are showing that it does not necessarily cause bias (DinizFilho et al. 2003). However, spatial autocorrelation analysis should still be conducted as it can serve as an important method for elucidating the mechanisms affecting the spatial structure of populations (DinizFilho et al. 2003).

To account for spatial autocorrelation we ran ALR models, which include autocovariance as a variable and, therefore, account for the spatial autocorrelation in the data. In some cases, the ALR caused some of the variables found important to the distribution of fish in the GLMs to become insignificant. The comparison between the models (i.e. AIC) showed that the ALR models were more robust; however, because we could not predict the autocovariance over the entire study area, we could not create a predictive distribution grid and were unable to compare the predictive power of the models using an evaluation data set. In future studies, more exploration into the use of kriging to create a map of spatial autocorrelation over the extent of the study area would allow for the creation of predictive distribution maps that include spatial autocorrelation as a variable (Augustin et al. 1996, Miller \& Franklin 2006). Even though Dormann (2007) showed that regression often undervalues the effect of environmental variables and, as a result, gives biased estimates when compared with nonspatial logistic regression models, such as GLMs, it is still important to explore the effect that spatial autocorrelation has on the predictive power of the data set.

\section{Limitations of approach}

A potential problem with the models used in this study is that they rely only on indirect predictor variables (e.g. slope, VRM, topographic position, distance to rock), which have no direct physiological relevance for species' performance. Relying solely on indirect variables tends to limit the geographical range across which a model can be applied successfully. Therefore, these models could be improved if resource variables (e.g. nutrients, food) and other direct variables (e.g. temperature, $\mathrm{pH}$ ) were incorporated into the GLMs rather than simply relying on benthic habitat features (Guisan \& Zimmermann 2000). Therefore, the models used in this study predict potential habitat. On the other hand, it is difficult and time consuming, if not impossible, to collect data for most direct variables, particularly at the spatial scales supported by multibeam sonar data, and some may be difficult to incorporate into these types of models.

Another important variable that these models do not take into account is fishing pressure, a factor that can limit the geographical extent of a given model's applic- 
ability. A model that is developed in a protected area where little fishing effort occurs could adequately define suitable habitat and accurately predict the presence/absence of fish. However, if the same model were transferred to a location of higher fishing pressure, the model may predict suitable habitat well but not actual presence.

This study only explored the use of GLMs to determine the probability of occurrence of the rockfish species. Another type of model that could potentially provide more robust predictions is the GAM. GAMs are similar to GLMs in that they can be used with data that are nonlinear and have nonconstant variance (Yee \& Mitchell 1991, Guisan et al. 2002). GLMs do not always have the ability to approximate the true regression surface, especially if the true curve is asymmetrical.

Finally, these models are based on a 'snapshot' of habitat use by these fish species. More robust models in the future will include movement data and provide more understanding of the scale at which species are associated with their habitat, as well as their habitat use over longer time periods and how often they move between different habitat types. Acoustic tracking of fish will enable more robust modeling approaches to predicting the distribution of fish.

The combination of these limitations can make it difficult to transfer these spatially explicit models to other locations to predict the presence/absence of fish. However, Iampietro et al. (2008) successfully used one of the models from Cordell Bank to accurately predict the occurrence of Sebastes flavidus on the shale beds in Monterey, California. That study showed that at least one of the species responded to the same types of habitat features in a different location.

\section{Implications for management}

Despite their limitations, these types of speciesspecific landscape models show great promise in their ability to accurately predict the distribution of demersal groundfish species. As a result, they should prove useful in the fields of conservation biology and fisheries management, particularly when applied to the design and selection of MPAs and the identification of essential fish habitat (EFH) (Pittman et al. 2004, 2007). Because habitat distribution and preference play a large role in the structuring of fish assemblages, indentifying suitable habitat for the species of interest is crucial to the successful design of MPAs (Love et al. 2006). Moreover, these models provide an efficient method for determining the benthic habitat characteristics of importance to different species and could be used to define the distribution of suitable potential habits for the restoration of targeted species in depleted areas.

\section{CONCLUSIONS}

Previously, limitations in the resolution and coverage of bathymetric maps have made it difficult to develop correlations between species and their habitats based on this information (Nasby-Lucas et al. 2002). In the present study, using landscape ecology modeling techniques applied to high-resolution, acoustic remote sensing data we have demonstrated that the results from detailed but narrowly confined visual surveys can be accurately and efficiently extrapolated across broad areas of the seafloor. In addition to the management of marine fishes, these types of models could also be applied to a number of marine organisms. Now, with the rapidly growing volume of high-resolution bathymetric data being collected along continental margins, there is a need for spatially referenced species observations and movement data within the coastal areas for the broad implementation of these types of speciesspecific habitat models. Moreover, repeat mapping will create the time series needed to assess habitat change and temporal variability in quality and preference, both critical to MPA and fisheries performance.

Acknowledgements. Primary funding for this research was provided by the Cordell Bank National Marine Sanctuary, with additional support from the NOAA funded CICORE program. We thank D. Howard, D. Roberts and L. Etherington from Cordell Bank National Marine Sanctuary for providing access to all the biological and physical data identified through the 2002 video transects and for constructive comments and suggestions in the beginning stages of this project, and C. Bretz and the RC Lab for their edits and suggestions on this manuscript. We are grateful to the staff at the Seafloor Mapping Lab at California State University, Monterey Bay, especially those who helped collect the multibeam data (C. Bretz, D. Minard, K. Thomas and S. Zurita).

\section{LITERATURE CITED}

Anderson TJ, Yoklavich MM (2007) Multiscale habitat associations of deepwater demersal fishes off central California. Fish Bull 105:168-179

Anderson TJ, Syms C, Roberts DA, Howard DF (2009) Multiscale fish-habitat associations and the use of habitat surrogates to predict the organization and abundance of deepwater fish assemblages. J Exp Mar Biol Ecol 379:34-42

- Augustin NH, Mugglestone MA, Buckland ST (1996) An autologistic model for the spatial distribution of wildlife. J Appl Ecol 33:339-347

Auster PJ, Lindholm J, Valentine PC (2003) Variation in habitat use by juvenile Acadian redfish, Sebastes fasciatus. Environ Biol Fishes 68:381-389

Austin MP (1998) An ecological perspective on biodiversity investigations: examples from Australian eucalypt forests. Ann Mo Bot Gard 85:2-17

Austin MP, Nicholls AO, Doherty MD, Meyers JA (1994) Determining species response functions to an environmental gradient by means of a $\beta$-function. J Veg Sci 5:215-228

Bryan TL, Metaxas A (2007) Predicting suitable habitat for deep-water gorgonial corals on the Atlantic and Pacific con- 
tinental margins of North America. Mar Ecol Prog Ser 330: 113-126

CARIS 2006. CARIS HIPS and SIPS 6.1 user's guide. Fredericton, NB (www.caris.com)

- Cochrane GR, Lafferty KD (2002) Use of acoustic classification of sidescan sonar data for mapping benthic habitat in the Northern Channel Islands, California. Cont Shelf Res 22: 683-690

Cohen J (1960) A coefficient of agreement for nominal scales. Educ Psychol Meas 20:37-46

Diniz-Filho JAF, Bini LM, Hawkins BA (2003) Spatial autocorrelation and red herrings in geographical ecology. Glob Ecol Biogeogr 12:53-64

$>$ Dormann CF (2007) Assessing the validity of autologistic regression. Ecol Model 207:234-242

$>$ Dunn DC, Halpin PN (2009) Rugosity-based regional modeling of hard-bottom habitat. Mar Ecol Prog Ser 377:1-11

Engler R, Guisan A, Rechsteiner L (2004) An improved approach for predicting the distribution of rare and endangered species from occurrence and pseudo-absence data. J Appl Ecol 41:263-274

Fernandez N, Delibes M, Palomares F, Mladenoff DJ (2003) Identifying breeding habitat for the Iberian lynx: inferences from fine-scale spatial analysis. Ecol Appl 13:1310-1324

Friedlander AM, Parrish JD (1998) Habitat characteristics affecting fish assemblages on a Hawaiian coral reef. J Exp Mar Biol Ecol 224:1-30

Guisan A, Zimmermann NE (2000) Predictive habitat distribution models in ecology. Ecol Model 135:147-186

> Guisan A, Edwards TC, Hastie T (2002) Generalized linear and generalized additive models in studies of species distributions: setting the scene. Ecol Model 157:89-100

Hirzel A, Guisan A (2002) Which is the optimal sampling strategy for habitat suitability modelling. Ecol Model 157: 331-341

Hirzel AH, Hausser J, Chessel D, Perrin N (2002) Ecologicalniche factor analysis: How to compute habitat-suitability maps without absence data? Ecology 83:2027-2036

Hobson RD (1972) Surface roughness in topography: quantitative approach. In: Chorley RJ (ed) Spatial analysis in geomorphology. Harper \& Row, New York, p 221-245

Hughes Clarke JE, Mayer LA, Wells DE (1996) Shallow-water imaging multibeam sonars: a new tool for investigating seafloor processes in the coastal zone and on the continental shelf. Mar Geophys Res 18:607-629

- Iampietro PJ, Kvitek RG, Morris E (2005) Recent advances in automated genus-specific marine habitat mapping enabled by high-resolution multibeam bathymetry. Mar Technol Soc Ser 39:83-93

Iampietro PJ, Young MA, Kvitek RG (2008) Multivariate prediction of rockfish habitat suitability in Cordell Bank National Marine Sanctuary and Del Monte Shalebeds, California, USA. Mar Geod 31:359-371

Intelmann SS, Cochrane GR (2006) Benthic habitat mapping in the Olympic Coast National Marine Sanctuary: classification of sidescan sonar data from survey HMPR-1082002-01: version I. Marine Sanctuaries Conservation Series ONMS-06-01, Silver Spring, MD

$>$ Jackson VL, Laack LL, Zimmerman EG (2005) Landscape metrics associated with habitat use by ocelots in south Texas. J Wildl Manag 69:733-738

Jagielo T, Hoffmann A, Tagart J, Zimmermann M (2003) Demersal groundfish densities in trawlable and untrawlable habitats off Washington: implications for the estimation of habitat bias in trawl surveys. Fish Bull 100:545-565

Kleinwachter M, Rickfelder T (2007) Habitat models for a riparian carabid beetle: their validity and applicability in the evaluation of river bank management. Biodivers Conserv 16:3067-3081

> Landis JR, Koch GG (1977) The measurement of observer agreement for categorical data. Biometrics 33:159-174

Leathwick J, Moilanen A, Francis M, Elith J and others (2008) Novel methods for the design and evaluation of marine protected areas in offshore waters. Conserv Lett 1:91-102

Legendre P (1993) Spatial autocorrelation: Trouble or new paradigm? Ecology 74:1659-1673

Li J, Hilbert DW (2008) LIVES: a new habitat modelling technique for predicting the distribution of species' occurrences using presence-only data based on limiting factor theory. Biodivers Conserv 17:3079-3095

> Lindholm JB, Auster PJ, Ruth M, Kaufman L (2001) Modeling the effects of fishing and implications for the design of marine protected areas: juvenile fish responses to variation in seafloor habitat. Conserv Biol 15:424-437

Love MS, Yoklavich M, Thorsteinson L (2002) The rockfishes of the northeast Pacific. University of California Press, Berkeley, CA

Love MS, Schroeder DM, Lenarz B, Cochrane GR (2006) Gimme shelter: the importance of crevices to some fish inhabiting a deeper-water rocky outcrop in southern California. CCOFI Rep 47:119-126

- Lundblad ER, Wright DJ, Miller J, Larkin EM and others (2006) A benthic terrain classification scheme for American Samoa. Mar Geod 29:89-111

MacArthur R, Levins R (1964) Competition, habitat selection and character displacement in a patchy environment. Proc Natl Acad Sci USA 51:1207-1210

MacMahon JA (1997) Ecological restoration. In: Meffe GK, Carroll CR (eds) Principles of conservation biology, 2nd edn. Sinauer, Sunderland, MA, p 479-511

Margules CR, Austin MP (eds) (1991) Nature conservation: cost effective biological surveys and data analysis. Commonwealth Scientific and Industrial Research Organisation (CSIRO), Melbourne

> McClatchie S, Millar RB, Webster F, Lester PJ, Hurst R, Bagley N (1997) Demersal fish community diversity off New Zealand: Is it related to depth, latitude and regional surface phytoplankton? Deep-Sea Res I 44:647-667

McCullagh P, Nelder JA (1989) Generalized linear models. Chapman \& Hall, London

Miller J, Franklin J (2006) Explicitly incorporating spatial dependence in predictive vegetation models in the form of explanatory variables: a Majave Desert case study. J Geogr Syst 8:411-435

Nasby-Lucas NM, Merle SG, Embley BW, Tissot BN, Hixon MA, Wright DJ (2002) Integration of submersible transect data and high-resolution multibeam sonar imagery for a habitat-based groundfish assessment of Heceta Bank, Oregon. Fish Bull 100:739-751

> Pittman SJ, McAlpine CA, Pittman KM (2004) Linking fish and prawns to their environment: a hierarchical landscape approach. Mar Ecol Prog Ser 283:233-254

Pittman SJ, Christensen JD, Caldow C, Menza C, Monaco ME (2007) Predictive mapping of fish species richness across shallow-water seascapes in the Caribbean. Ecol Model 204: 9-21

Pittman SJ, Costa BM, Battista TA (2009) Using LIDAR bathymetry and boosted regression trees to predict the diversity and abundance of fish and corals. J Coast Res 53:27-38

Posada D, Buckley TR (2004) Model selection and model averaging in phylogenetics: advantages of Akaike Information Criterion and Bayesian approaches over Likelihood Ratio Tests. Syst Biol 53:793-808

R Development Core Team (2007) R: a language and environ- 
ment for statistical computing. R Foundation for Statistical Computing, Vienna (www.R-project.org)

Rhodes JR, McAlpine CA, Lunney D, Possingham HP (2005) A spatially explicit habitat selection model incorporating home range behavior. Ecology 86:1199-1205

Roberts JJ, Best BD, Dunn DC, Treml EA, Halpin PN (2010) Marine geospatial ecology tools: an integrated framework for ecological geoprocessing with ArcGIS, Python, R, MATLAB, and C++. Environ Model Software 25:1197-1207

Rotenberry JT, Preston KL, Knick ST (2006) GIS-based niche modeling for mapping species' habitat. Ecology 87: 1458-1464

Rubec PJ, Coyne MS, McMichael RH Jr, Monaco ME (1998) Spatial methods being developed in Florida to determine essential fish habitat. Fisheries 23(7):21-25

Sappington JM, Longshore KM, Thomson DB (2007) Quantifiying landscape ruggedness for animal habitat analysis: a case study using bighorn sheep in the Mojave Desert. J Wildl Manag 71:1419-1426

Scott JM, Heglund PJ, Morrison ML, Haufler JB, Raphael MG, Wall WA, Samson FB (2002) Predicting species occurrences: issues of accuracy and scale. Island Press, Washington, DC

Segurado P, Araujo MB, Kunin WE (2006) Consequences of spatial autocorrelation for niche-based models. J Appl Ecol 43:433-444

Triton Imaging (2005) Isis application. Triton Imaging, Watsonville, CA

Valavanis VD, Pierce GJ, Zuur AF, Palialexis A, Saveliev A,

Editorial responsibility: John Choat,

Townsville, Australia
Katara I, Wang J (2008) Modelling of essential fish habitat based on remote sensing, spatial analysis and GIS. Hydrobiologia 612:5-20

Walker BK, Jordan LKB, Spieler RE (2009) Relationship of reef fish assemblages and topographic complexity on Southeastern Florida coral reef habitats. J Coast Res 53:39-48

Weiss A (2001) Topographic position and landforms analysis. ESRI User Conference, 12-16 Jul 2001, San Diego, CA (Poster)

Williams EH, Ralston S (2002) Distribution and co-occurrence of rockfishes (family: Sebastidae) over trawlable shelf and slope habitats of California and southern Oregon. Fish Bull 100:836-855

Wintle BA, Bardos DC (2006) Modeling species-habitat relationships with spatially autocorrelated observation data. Ecol Appl 16:1945-1958

Yee TW, Mitchell ND (1991) Generalized additive models in plant ecology. J Veg Sci 2:587-602

Yoklavich MM, Greene GH, Cailliet GM, Sullivan DE, Lea RN, Love MS (1999) Habitat associations of deep-water rockfishes in a submarine canyon: an example of natural refuge. Fish Bull 98:625-641

> Yoklavich MM, Love MS, Forney KA (2007) A fishery-independent assessment of an overfished rockfish stock, cowcod (Sebastes levis), using direct observations from an occupied submersible. Can J Fish Aquat Sci 64:1795-1804

Zawada DG, Brock JC (2009) A multiscale analysis of coral reef topographic complexity using lidar-derived bathymetry. J Coast Res 53:6-15

Submitted: December 7, 2009; Accepted: August 4, 2010 Proofs received from author(s): September 6, 2010 